\title{
Procedural Approach for Designing Skip-lot Sampling Plan of type SkSP-T through Minimum Sum of Risks
}

\author{
K. Pradeepa Veerakumari ${ }^{1 *}$, S. Suganya ${ }^{2}$ \\ ${ }^{1}$ Department of Statistics, Bharathiar University, Coimbatore, Tamil Nadu, India \\ ${ }^{2}$ Department of Statistics, Bharathiar University, Coimbatore, Tamil Nadu, India \\ *Corresponding Author: sadeep_13@yahoo.co.in, Tel.: +919443937722
}

Available online at: www.isroset.org

Received: 31/May/2018, Revised: 07/Jun/2018/2018, Accepted: 18/Jun/2018, Online: 30/Jun/2018

\begin{abstract}
The principal objective of this paper is to evaluate optimal plan parameters for Skip-lot Sampling Plan of type SkSP-T with single sampling plan as reference plan involving minimum sum risks. The designing technique includes the assessment of Acceptable Quality Level (AQL) and Limiting Quality Level (LQL) taking in to account the proper balancing of Producer and Consumer risks. Tables are simulated for various parametric values of SkSP-T with Single Sampling Plan.
\end{abstract}

Keywords - SkSP-T, Minimum sum of risks, AQL, LQL, Single Sampling plan.

\section{INTRODUCTION}

Acceptance sampling plan in Statistical Quality Control concerns about acceptance or rejection of the submitted lot of a huge amount of products on the source of the excellent quality of products inspected throughout the sample taken from the lot. Acceptance sampling techniques defend consumer against the risk of accepting the poor quality of lots as well as the producer against the risk of rejecting a good quality at various consumers and producers levels. Dodge and Romig derived and developed many techniques about acceptance sampling plans for inspecting the finished products and the products based on the sampling inspection outcomes. The acceptance sampling procedures used in the production process gives the defect free items and less production cost and maintenance cost.

Dodge introduced the first skip-lot sampling plan of type SkSP-1 [1]. SkSP-1 is only the theoretical basis and in this plan has followed by Continuous Sampling Plan of type CSP-1. Dodge and Perry introduced Skip-lot Sampling Plan of type SkSP-2 [2]. Perry has derived the Operating Characteristics (OC) and ASN functions of SkSP-2 plan [3]. Skip-lot plan of type SkSP-2 is used an attribute inspection sampling plan it is called as "reference sampling plan". For SkSP-2 Perry has use Single Sampling plan as reference plan in the provision of Poisson distribution. Soundararajan and Vijayaraghavan introduced the new structure of skip-lot sampling plan; it is designated as SkSP-3 [4]. It is based on the concept of continuous sampling plan of type CSP-2. Balamurali and Chi-Hyuck Jun proposed and resultant the new skip-lot sampling plan, which is designated as SkSP-V [5]. In SkSP-V plan also based on the CSP's consist of CSP-V. Balamurali et.al proposed the skip-lot sampling plan includes resampling plans, which is designated as SkSP-R (Resampling) [6].

The Continuous Sampling Plan of type CSP-T plans is tightened multilevel plans which incorporate three levels designed by Fordice [7]. Kandasamy and Govindaraju used Markov Chain (MC) models to derive the operating functions of CSP-T plan [8]. Balamurali proposed Modified Tightened Three level Continuous sampling plan [9]. Balamurali and Chi-Hyuck Jun proposed a modified CSP-T sampling procedure [10].

Pradeepa Veerakumari and Suganya (2016) proposed and derived a new system of Skip-lot sampling plan of type SkSP-T [11, 12]. SkSP-T is mainly based on the concept CSP-T, CSP-M, MMLP-T-2 and SkSP-2. Sampling levels are predetermined by using CSP-M sampling procedure; sampling fractions are taken from the CSP-T sampling plan procedure and other concepts are taken by modified CSP-T and SkSP-2 procedures. The main advantage of skip-lot sampling plan of type SkSP-T plan if there is a defect found in skipping level, then there is a normal inspection in that fraction level. 


\section{MINIMUM SUM OF RISK}

Golub proposed the new model it is called as minimum sum of producer and consumer risks for Single Sampling plan then the sample size (n) is fixed by changing the acceptance number (c) [13]. Soundararajan has developed the minimum sum of risks for single sampling plan under the condition of Poisson model using Golub's sampling approach [14]. Vijayathilakan and Soundararajan extended the Golub's approach for Hypergeometric model [15]. In the hypergeometric model weighted risk is designing for single sampling plan and the sample size $\mathrm{n}$ is fixed. Vijayaraghavan explained the Multi Deferred State Sampling plan using the Minimum sum of risks plan for particular AQL and LQL values through the minimum sum of risks [16]. Subramani developed the RGS plan through Minimum sum of risk [17]. The minimum sum of producer's and consumer's risks is defined by the following mathematical expression

$\alpha+\beta=P_{a}\left(p_{1}\right)+\left(1-P_{a}\left(p_{2}\right)\right)$

$\mathrm{P}_{\mathrm{a}}\left(\mathrm{p}_{1}\right)$ - Probability of Accepting the lot quality $\mathrm{p}_{1}$

$\mathrm{P}_{\mathrm{a}}\left(\mathrm{p}_{2}\right)$ - Probability of Rejecting the lot quality $\mathrm{p}_{2}$

The alternative formula for the minimum the sum of producer's and consumer's risk as $1-\mathrm{P}_{\mathrm{a}}\left(\mathrm{p}_{1}\right)+\mathrm{P}_{\mathrm{a}}\left(\mathrm{p}_{2}\right)$. Golub has extended the minimum sum of risk concept for fixed sample size (n), and the acceptance number which minimize using the following expression.

$\frac{n}{\frac{\log p_{2}-\log p_{1}}{\log \left(1-p_{1}\right)-\log \left(1-p_{2}\right)}+1}-\frac{1}{2}$

The OR (Operating Ratio $=\mathrm{p}_{2} / \mathrm{p}_{1}$ ) and $\mathrm{np}_{1}$ values are known, then calculate the $n p_{2}$ value as

$n p_{2}=\left(\frac{p_{2}}{p_{1}}\right)\left(n p_{1}\right)$

\section{Advantages of Minimum Sum of risk}

- The minimum sum of risks for consumer and producer risk plans are better discriminating among lots of good quality and poor quality.

- When the consumer and the producer belong to the same company or interest, both the risks may be minimized moderately then the risk levels are fixed.

\section{OPERATING PROCEDURE FOR SKSP-T}

Operating procedure of the SkSP-T plan is stated as follows:

$>$ Initiate SkSP-T procedure with normal inspection using single sampling plan as reference plan.
$>$ When $i$ consecutive lots are accepted on normal inspection, discontinue the normal inspection and switch to skipping inspection.

$>$ On skipping inspection, inspect only a fraction $f$ of the lots selected at random, level 1.

$>$ After $i$ consecutive lots in succession have been found without a non-conforming at level 1, the system then switches to skipping inspection with a fraction of $f / 2$, level 2.

$>$ After $i$ consecutive lots in succession have been found without a non-conforming at level 2, the system then switches to skipping inspection with a fraction of $f / 4$, level 3.

$>$ If a non-conforming lot is found on either skipping level, the system reverts to normal inspection.

$>$ Exchange all non-conforming lots establish with conforming once.

\section{OPERATING CHARACTERISTIC FUNCTION FOR SkSP-T PLAN}

The Operating Characteristics function for SkSP-T plan is given as

$$
\begin{aligned}
& P_{a}(p)= \\
& \frac{p^{i}\left(f_{2} f_{3}\left(1-p^{i}\right)+f_{1} f_{3} p^{i}\left(1-p^{i}\right)+f_{1} f_{2} p^{2 i}\right)}{f_{1} f_{2} f_{3}\left(1-p^{i}\right)+p^{i}\left(f_{2} f_{3}\left(1-p^{i}\right)+f_{1} f_{3} p^{i}\left(1-p^{i}\right)+f_{1} f_{2} p^{2 i}\right)}
\end{aligned}
$$

Where, $\mathrm{P}=$ Probability of Acceptance of the single sampling plan, $f$ is the sampling frequency and $i$ is the clearance number.

\section{CONSTRUCTION OF TABLE}

The Operating Characteristics function for SkSP-T plan with Single Sampling Plan as the Reference Plan as follows

$$
\begin{aligned}
& P_{a}(p)= \\
& \frac{p^{i}\left(f_{2} f_{3}\left(1-p^{i}\right)+f_{1} f_{3} p^{i}\left(1-p^{i}\right)+f_{1} f_{2} p^{2 i}\right)}{f_{1} f_{2} f_{3}\left(1-p^{i}\right)+p^{i}\left(f_{2} f_{3}\left(1-p^{i}\right)+f_{1} f_{3} p^{i}\left(1-p^{i}\right)+f_{1} f_{2} p^{2 i}\right)}
\end{aligned}
$$

Where, $\mathrm{P}_{\mathrm{a}}(\mathrm{p})$ is the Probability of Acceptance of the Single Sampling Plan as Reference plan. In this equation can be formulated by many parameter values of SkSP-T and SSP.

\section{Designing plans for given AQL, LQL, $\alpha$ AND $\beta$}

1. Specify $\mathrm{p}_{1}=$ Acceptable Quality Level at $\alpha=0.05$ or 0.01 . 2. Specify $\mathrm{p}_{2}=$ Limiting Quality Level at $\beta=0.10$ or 0.05 .

3. Obtain the corresponding operating ratio $\mathrm{OR}=\mathrm{p}_{2} / \mathrm{p}_{1}$ at different combination of $\alpha$ and $\beta$.

4. The actual $n p_{1}$ and $n p_{2}$ values corresponding to the OR value has been noted. 


\section{SELECTION OF MINIMUM SUM OF RISK FOR SKIP-LOT SAMPLING PLAN OF TYPE SKSP-T WITH SINGLE SAMPLING PLAN AS REFERENCE PLAN}

From table 1 is used to determine the minimum sum of risks for Skip-lot sampling plan of type SkSP-T for given $\mathrm{p}_{1}$ and $\mathrm{p}_{2}$. From this table, the producer risk and consumer risk will be determined at most $10 \%$ each. And the Operating Ratio $(\mathrm{OR})=\mathrm{p}_{2} / \mathrm{p}_{1}$ values are fixed. The obtaining values of the table $\alpha, \beta, \mathrm{i}, \mathrm{f}_{1}, \mathrm{f}_{2}, \mathrm{f}_{3}$ and c. $\alpha$ - Producer's Risk, $\beta-$
Consumer's Risk, i- Clearance number, f- Sampling frequency and c- Acceptance number.

\section{Numerical Illustration}

For given $\mathrm{p}_{1}=0.0043$ and $\mathrm{p}_{2}=0.0299$ at $\alpha=0.10$ and $\beta=$ 0.10 . Then the Operating ratio $\mathrm{OR}=6.95 \approx 7$. And the $n \mathrm{p}_{2}$ value is determine as $\mathrm{np}_{2}=\left(\mathrm{p}_{2} / \mathrm{p}_{1}\right)\left(\mathrm{np}_{1}\right)=$ $(0.0299 / 0.0043) *(0.4)=(6.95 * 0.4)=2.8$. From the table Operating ratio $\left(\mathrm{p}_{2} / \mathrm{p}_{1}\right)$ and $\mathrm{np}_{1}$ values are fixed, the corresponding Producer $(\alpha)$ and consumer $(\beta)$ risks are determined.

Table1: Using various parameters values of skip lot sampling plan of type SkSP-T and Single Sampling plan for given OR and $\mathbf{n p}_{1}$ values $\left(\alpha, \beta, \mathrm{f}_{1}, \mathrm{f}_{2}, \mathrm{f}_{3}\right.$ and $\left.\mathrm{c}\right)$

\begin{tabular}{|c|c|c|c|c|c|}
\hline $\mathbf{n p}_{1}$ & \multicolumn{5}{|c|}{$\mathbf{n p}_{1}$} \\
\hline OR & 0.50 & 1.0 & 1.5 & 2.0 & 3.0 \\
\hline 3 & $\begin{array}{c}0.05,0.10,4,0.5 \\
0.250 .125,2\end{array}$ & $\begin{array}{c}0.10,0.10,3,0.5 \\
0.25,0.125,2\end{array}$ & $\begin{array}{c}0.10,0.10,2,0.5 \\
0.25,0.125,2\end{array}$ & $\begin{array}{c}0.10,0.10,1,0.5 \\
0.25,0.125,2\end{array}$ & $\begin{array}{c}0.10,0.05,1,0.5 \\
0.25,0.125,3\end{array}$ \\
\hline 4 & $\begin{array}{c}0.10,0.10,3,0.3 \\
0.15,0.075,1\end{array}$ & $\begin{array}{c}0.10,0.10,2,0.5 \\
0.25,0.125,1\end{array}$ & $\begin{array}{c}0.1,0.05,1,0.3 \\
0.15,0.075,1\end{array}$ & $\begin{array}{c}0.10,0.05,1,0.2 \\
0.10,0.05,1\end{array}$ & $\begin{array}{c}0.10,0.01,1,0.5 \\
0.25,0.125,3\end{array}$ \\
\hline 5 & $\begin{array}{c}0.10,0.10,1,0.3 \\
0.15,0.075,0\end{array}$ & $\begin{array}{c}0.05,0.05,1,0.3 \\
0.15,0.075,1\end{array}$ & $\begin{array}{c}0.1,0.01,1,0.3 \\
0.15,0.075,1\end{array}$ & $\begin{array}{c}0.05,0.05,1,0.3 \\
0.15,0.075,2\end{array}$ & $\begin{array}{c}0.10,0.01,1,0.3, \\
0.15,0.075,2\end{array}$ \\
\hline 6 & $\begin{array}{c}0.05,0.05,2,0.5 \\
0.25,0.125,0\end{array}$ & $\begin{array}{c}0.05,0.05,2,0.5 \\
0.25,0.125,1\end{array}$ & $\begin{array}{c}0.01,0.1,1,0.3 \\
0.15,0.075,2\end{array}$ & $\begin{array}{c}0.05,0.01,1,0.3 \\
0.15,0.075,2\end{array}$ & $\begin{array}{c}0.01,0.05,1,0.3, \\
0.15,0.075,3\end{array}$ \\
\hline 7 & $\begin{array}{c}0.01,0.01,3,0.3 \\
0.15,0.075,2\end{array}$ & $\begin{array}{c}0.05,0.05,2,0.3 \\
0.25,0.125,2\end{array}$ & $\begin{array}{c}0.01,0.10,1,0.3, \\
0.15,0.075,1\end{array}$ & $\begin{array}{l}0.1,0.1,1,0.3, \\
0.15,0.075,2\end{array}$ & $\begin{array}{c}0.05,0.1,1,0.3 \\
0.15,0.075,2\end{array}$ \\
\hline 8 & $\begin{array}{c}0.10,0.10,2,0.3, \\
0.15,0.075,0\end{array}$ & $\begin{array}{c}0.05,0.10,1,0.20 \\
0.10,0.05,0\end{array}$ & $\begin{array}{c}0.01,0.01,3,0.5 \\
0.25,0.125,0\end{array}$ & $\begin{array}{c}0.01,0.01,1,0.2 \\
0.10,0.05,2\end{array}$ & $\begin{array}{c}0.05,0.1,1,0.20 \\
0.10,0.05,2\end{array}$ \\
\hline 9 & $\begin{array}{c}0.10,0.10,2,0.5 \\
0.25,0.125,0\end{array}$ & $\begin{array}{c}0.05,0.05,1,0.2 \\
0.10,0.05,0\end{array}$ & $\begin{array}{c}0.01,0.01,1,0.3, \\
0.15,0.075,2\end{array}$ & $\begin{array}{c}0.01,0.01,2,0.5 \\
0.25,0.125,3\end{array}$ & $\begin{array}{c}0.01,0.1,1,0.2 \\
0.10,0.05,3\end{array}$ \\
\hline 10 & $\begin{array}{c}0.10,0.10,3,0.3 \\
0.15,0.075,0\end{array}$ & $\begin{array}{c}0.10,0.10,1,0.5 \\
0.25,0.125,1\end{array}$ & $\begin{array}{c}0.01,0.05,2,0.2 \\
0.10,0.05,1\end{array}$ & $\begin{array}{c}0.05 .05,1,0.3 \\
0.15,0.075,2\end{array}$ & $\begin{array}{c}0.01,0.01,2,0.5 \\
0.25,0.125,1\end{array}$ \\
\hline 11 & $\begin{array}{c}0.1,0.05,2,0.5 \\
0.25,0.125,0\end{array}$ & $\begin{array}{c}0.01,0.10,3,0.2 \\
0.10,0.05,1\end{array}$ & $\begin{array}{c}0.10,0.05,1,0.5 \\
0.25,0.125,1\end{array}$ & $\begin{array}{c}0.1,0.05,1,0.2 \\
0.10,0.05,2\end{array}$ & $\begin{array}{c}0.01,0.01,2,0.3 \\
0.15,0.075,1\end{array}$ \\
\hline 12 & 4 & $\begin{array}{c}0.01,0.01,1,0.2 \\
0.10,0.05,1\end{array}$ & $\begin{array}{c}0.01,0.05,3,0.2 \\
0.10,0.05,1\end{array}$ & $\begin{array}{c}0.10,0.05,1,0.5, \\
0.25,0.125,2\end{array}$ & $\begin{array}{c}0.10,0.01,1,0.5 \\
0.25,0.125,2\end{array}$ \\
\hline 13 & & $\begin{array}{c}0.01,0.05,1,0.2 \\
0.10,0.05,1\end{array}$ & $\begin{array}{c}0.05,0.10,1,0.3, \\
0.15,0.075,1\end{array}$ & $\begin{array}{c}0.01,0.05,2,0.3 \\
0.15,0.075,1\end{array}$ & $\begin{array}{c}0.01,0.05,2,0.5 \\
0.25,0.125,1\end{array}$ \\
\hline 14 & & $\uparrow$ & $\begin{array}{c}0.05,0.05,2,0.2 \\
0.10,0.05,1\end{array}$ & $\begin{array}{c}0.10,0.05,2,0.3 \\
0.15,0.075,1\end{array}$ & $\begin{array}{c}0.01,0.01,3,0.3 \text {, } \\
0.015,0.075,1\end{array}$ \\
\hline 15 & & & & $\begin{array}{c}0.05,0.10,2,0.2 \\
0.10,0.05,1\end{array}$ & $\begin{array}{c}0.01,0.05,3,0.2 \\
0.10,0.05,1\end{array}$ \\
\hline 16 & & & & $\begin{array}{c}0.01,0.01,3,0.2 \\
0.10,0.05,1\end{array}$ & $\begin{array}{c}0.01,0.01,2,0.2 \\
0.10,0.05,1\end{array}$ \\
\hline 17 & & & & $\begin{array}{c}0.01,0.01,3,0.2 \\
0.10,0.05,1\end{array}$ & $\begin{array}{c}0.01,0.1,3,0.3 \\
0.10,0.075,1\end{array}$ \\
\hline
\end{tabular}

\section{CONCLUSION}

In acceptance sampling plan, specifying requirements of the producer and consumer plays a dominant role and $\mathrm{p}_{1}$ represents a satisfactory quality of producer and $\mathrm{p}_{2}$ represents a satisfactory quality of consumer. In practice, it is desired to design sampling plan with the associated quality levels which safeguard producer and consumer. Skip-lot sampling plan of type SkSP-T using single sampling plan has wide potential applicability in industries to ensure higher standard of quality attainment and increased customer satisfaction. Selection procedures considered in this paper uses the quality 
level associated with the minimum sum of producer's and consumer's risk.

\section{REFERENCES}

[1] Dodge H. F, "Skip-Lot sampling plan", Industrial Quality Control, 11(5), pp. 3-5, 1955.

[2] Dodg.H. F, Perry. R L, "A System of Skip-lot Plans for Lot-by-lot inspection", American society for Quality Control Technical Conference Transactions, Chicago, Illinois, pp.469-477, 1971.

[3] Perry R. L, "Skip lot Sampling Plans", Journal of Quality Technology, 5 (3), pp. 123-130, 1973.

[4] V. Soundararajan, R. Vijayaraghavan, "A New System of Skip-lot Sampling Inspection Plans of type SkSP-3", Quality of Progress and Development, Wiley Eastern, 1989.

[5] Balamurali S, Chi-Hyuck Jun, “ A New System of Skip-lot Sampling Plans having a Provision for Reducing Normal Inspection", Applied Stochastic Models in Business Industry, Vol.27, pp. 348-363, 2011.

[6] Saminathan Balamurali, Muhammad Aslam, and Chi-Hyuck Jun, "A New System of Skip-Lot Sampling Plans including Resampling”, The Scientific World Journal, pp.1-6, 2014.

[7] Fordice. J. J, “A Tightened Multi-Level Continuous Sampling Plan CSP-T", Report No.QEM 21230-10, Ammunition Procurement and Supply Agency, Joliety, Illinois, 1972

[8] Kandasamy C, Govindaraju K, "Selection of CSP-T plans", Communication in Statistics - Simulation and Computation, Vol. 22, No.1, pp. 265-283, 1993.

[9] Balamurali S, "Modified Tightened Three level Continuous sampling plan", Economic Quality Control, Vol. 17, p. 221-234, 2002.

[10] Balamurali, S, Chi-Hyuck Jun, "Modified CSP-T sampling procedures for continuous production process", Quality Technology and Quantitative Management, Vol. 1, No. 2, pp. 175188, 2004.

[11] Pradeepa Veerakumari. K and Suganya, "A New System of SkSP-T with Single Sampling Plan as Reference Plan", Research Journal of Mathematics and Statistics, Vol.4 (4), 1-6, 2016.

[12] Pradeepa Veerakumari. K and Suganya. S, "SkSP-T with Double Sampling Plan (DSP) as Reference Plan using Fuzzy Logic Optimization Techniques", International Journal of Pure and Applied mathematics, Vol.117, No.12, 409-418, 2017.

[13] Golub, A, "Designing single sampling inspection plans when the sample size is fixed", Journal of American of the American Statistical Association, 48, 278-288, 1953.

[14] Soundararajan, V, "Sampling Inspection plans when the sample size is fixed", Journal of Madras University, Section B, 44, 9-19, 1981.

[15] Vijayathilakan, J.P, "Studies in Lot Acceptance Procedures", Ph.D Thesis, Madras University, Tamil Nadu, 1982.

[16] Soundararajan, V and Vijayaraghavan, R., "On Designing Multi Deferred State Sampling plans Involving Minimum Risks", Journal of Applied Statistics, Vol. 16, No.1, pp.87-94, 1989.

[17] Subramani, K, "Studies on Designing Attribute Acceptance Sampling Plans with Emphasis on Chain Sampling Plans", $\mathrm{PhD}$ Thesis, Bharathiar University, Coimbatore, Tamil Nadu, 1991.

\section{AUTHORS PROFILE}

Ms. Dr. K. Pradeepa Veerakumari pursed M.Sc and Ph.D. Statistics from Bharathiar University, Coimbatore in 2004 \& 2009. She is currently working as Assistant Professor in Department of Statistics from Bharathiar University, Coimbatore since 2011. She is a Life member of ISPS and

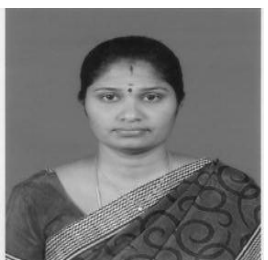
IISA since 2004. He has published more than 20 research papers in reputed National/International journals including Thomson Reuters (SCI/SCI-E, Scopes, Google Scholar \& Web of Science) and it's also available online. Her main research work focuses on Statistical Quality Control, Neural Network, Bayesian Sampling, Operations Research and Experts Systems. She has 9 years of teaching experience and 14 years of research experience. She has produced 4 Doctorates.

Ms. S. Suganya is now pursuing her $\mathrm{PhD}$ in the Department of Statistics, Bharathiar University, Coimbatore, Tamil Nadu, India. Her field of research is Acceptance Sampling Plan.

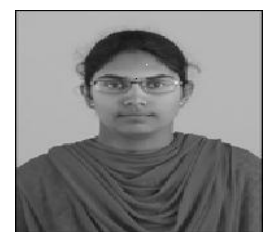

Note: Bharathiar University is an A grade University as per NAAC. Tody, the University was ranked as $13^{\text {th }}$ position by india. 